\title{
Alternative oxidizers in polyaniline synthesis
}

\author{
Jacek Niziol • Maciek Sniechowski • \\ Anna Podraza-Guba $\cdot$ Jan Pielichowski
}

Received: 1 February 2010/Revised: 16 May 2010/Accepted: 23 May 2010/

Published online: 4 June 2010

(C) The Author(s) 2010. This article is published with open access at Springerlink.com

\begin{abstract}
The article describes a modified method of polyaniline synthesis. The classical oxidizer-aqueous solution of hydrogen peroxide was replaced by different solid state hydrogen peroxide complexes, what helped keep constant temperature of the reaction mixture. The highest yield of the polymerization was obtained using urea-hydrogen peroxide.
\end{abstract}

Keywords Polyaniline $\cdot$ Hydrogen peroxide complex $\cdot$ Oxidizing polymerization

\section{Introduction}

Polyaniline (PANI) has been known since mid-XIX century under the name of aniline black, used for colorfast fabrics dyeing. Usually it has been synthesised in a one of three idealized oxidation states-leukoemeraldine, emeraldine, pernigraniline [1], containing different numbers of benzenoid and quinoid rings. A renaissance of interest in this polymer began in late 1980's owing to works published by MacDiarmid et al. [2], who discovered that protonation of emeraldine base made this material electrically conductive. Since that time a lot of effort has been put in improving different polyaniline properties. For example the reported electrical conductivity, has reached values in excess of $1,000 \mathrm{~S} / \mathrm{cm}$ [3]. Regardless of some processing problems, this polymer has already found numerous applications in

\footnotetext{
J. Niziol $(\bowtie) \cdot$ M. Sniechowski

Faculty of Physics and Applied Computer Science, AGH University of Science and Technology, al. Mickiewicza 30, 30-059 Krakow, Poland

e-mail: niziol@agh.edu.pl
}

\footnotetext{
A. Podraza-Guba · J. Pielichowski

Department of Chemistry and Technology of Polymers, Cracow University of Technology,

ul. Warszawska 24, 31-155 Krakow, Poland
} 
different fields. Among the others, it should be mentioned such technologies like electromagnetic shielding [4], conductive coatings [5], corrosion protection [6], artificial muscles [7], light-emitting diodes [8], field-effect transistors [9], photovoltaic cells [10] and sensors [11]. Polyaniline also can be used as an efficient catalyst in chemical technology, or as a catalyst substrate [12].

The most frequently implemented methods of aniline polymerization are based on chemical [13], electrochemical [14] or less often, biochemical [15] processes. There exist lots of their variants like polymerization carried on in emulsion [16] in order to enhance contact surface between organic monomer and inorganic oxidant, polymerization in non-aqueous environment $[17,18]$ and in low temperature plasma [19]. The polymerization method is determining factor for properties of the final product like chemical composition, oxidation state or average molecular weight. The synthesis able to provide bulk quantities of polyaniline is chemical synthesis. This is a simple process and hence intensively developed and improved. The chemical synthesis is performed in acidic environment and requires a strong oxidant to create aniline radical cations. Next, these cations undergo rearomatization and are coupled each to form growing pernigraniline chain. At the time when the oxidant is consumed, the remained excess of aniline reduces pernigraniline to emeraldine salt. The crucial role of the oxidant was emphasised by many researches. There are some oxidants more often reported in the bibliography than the others. This group constitute peroxydisulfate (VI) sodium or ammonium (MacDiarmid method) [20, 21], ammonium peroxydisulfate/ammonium cerium (IV) nitrate mixture [22], chromate (VI) potassium [23] and hydrogen peroxide [16].

Despite of the progress already achieved, from the industrial point of view the polyaniline is far from being a mature polymer, therefore there still exists need for a further amelioration of polyaniline properties and its synthesis.

The quality of chemically synthesised polyaniline as well as reproducibility of its properties depends a lot on the reaction temperature stability. Hence unpredictable temperature variations represent a significant drawback. A modified method of polyaniline synthesis, removing this effect is herein proposed. The method employs hydrogen peroxide in form of solid state complexes instead of traditional aqueous solution. These complexes are crystalline powders and can be introduced into the reaction environment without causing a sudden and hard to control increase of the reaction medium temperature, encountered if the hydrogen peroxide is applied as aqueous solution.

\section{Synthesis}

Starting chemicals used in this work were aniline, $\mathrm{FeCl}_{2}$, hydrochloric acid bought from POCH S.A., complex of urea-hydrogen peroxide (UHP) acquired from SigmaAldrich. Complexes of melamine-hydrogen peroxide (MHP) and of carbonate of sodium with hydrogen peroxide (SCHP) were kindly provided by Industrial Chemistry Research Institute in Warsaw, Poland. Characteristics of these complexes need not to be commented because they are widely used in the industry, owing to good oxidative, bleaching and disinfecting qualities [24]. 
Prior to the synthesis, aniline was distilled to remove products of aniline oxidation, which might have appeared during the storage. At the beginning $1 \mathrm{~mL}$ of aniline $(11 \mathrm{mmol})$ was poured into $30 \mathrm{~mL}$ of the aqueous $1 \mathrm{M}$ hydrochloric, and subsequently was added $2 \mathrm{~mL}$ of the aqueous solution including $0.02 \mathrm{mmol}$ catalyst $\left(\mathrm{FeCl}_{2}\right)$.

The mixture was intensively stirred and thermostated between -5 and $0{ }^{\circ} \mathrm{C}$ to minimize aniline side reactions. At the moment when temperature stabilized, $0.434 \mathrm{~g}(4.6 \mathrm{mmol})$ of the adduct UHP (oxidizing agent) was added in one shot but breaking of temperature stabilization was not observed. Afterwards the synthesis continued for either 6 or $24 \mathrm{~h}$. The resulting deposit was filtered off from reaction mixture, washed with abundance of distilled water until $\mathrm{pH}$ of 6-7 was reached and converted to its base form by treatment in ammonia solution for about $6 \mathrm{~h}$. At the end, the final product was extracted with methanol and tetrahydrofurane using Soxlet apparatus in order to remove oligomers residues.

The reaction was repeated replacing UHP oxidizer by melamine-hydrogen peroxide complex (MHP) in quantity $0.71 \mathrm{~g}(4.4 \mathrm{mmol})$ and carbonate of sodium hydrogen peroxide complex (SCHP) in quantity $0.7 \mathrm{~g}(5.0 \mathrm{mmol})$.

In Table 1 are summarized yields of aniline polymerization in relation to reaction time and type of complex of hydrogen peroxide. The structure of obtained powder was identified as emeraldine base by mean of standard techniques like infrared spectroscopy, UV-vis spectroscopy and thermogravimetric analysis. A part of each synthesised polyaniline batch was separated, immersed in $1 \mathrm{M}$ aqueous hydrochloric acid and stirred overnight. The next day the powder was filtered off, dried in technical vacuum and compressed in $0.5 \mathrm{~mm}$ thick pellets under the load of 15 ton lasting for $20 \mathrm{~min}$. These pellets were used for further electrical and X-ray diffraction studies.

\section{Infrared spectroscopy}

Polyaniline (emeraldine) consists of benzenoid and chinoid rings bridged through amine group as is shown in the Fig. 1. Infrared spectra in transmittance mode were measured on powder of the synthesized product dispersed in $\mathrm{KBr}$ pellets using FT-IR spectrophotometer BIO-RAD model FTS-165. All bands visible in the FT-IR spectrum suggested that the investigated compound was polyaniline in oxidation

Table 1 Oxidation polymerization reaction yields using three different complexes of hydrogen peroxide as an oxidizing agent and $\mathrm{FeCl}_{2}$ as a catalyst

\begin{tabular}{lcll}
\hline Complex HP & Process duration $(\mathrm{h})$ & Yield $(\%)$ & Sample reference \\
\hline UHP & 6 & 60 & EB4 \\
& 24 & 65 & \\
MHP & 6 & 20 & EB2 \\
& 24 & 40 & \\
SCHP & 6 & 30 & EB1 \\
& 24 & 50 & \\
\hline
\end{tabular}




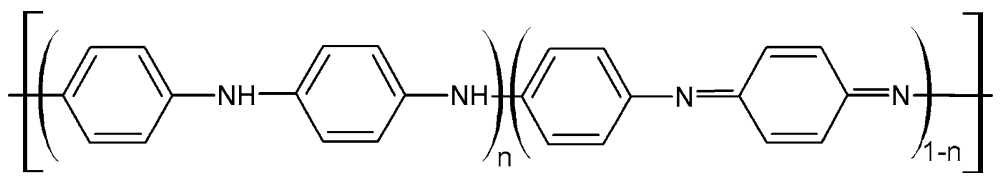

Fig. 1 Leucoemeraldine $n=1$, emeraldine base, $n=0.5$, pernigraniline $n=0$

state of emeraldine. In the plot shown in Fig. 2, it may be distinguished a band centred in the vicinity of $820 \mathrm{~cm}^{-1}$, usually assigned to deformation vibrations of aromatic rings in para position and bands falling in the range of $1,440-1,520 \mathrm{~cm}^{-1}$ interpreted as an evidence of vibrations of skeletal aromatic rings. Characteristic stretch vibrations of $-\mathrm{C}=\mathrm{C}-$ and $=\mathrm{C}-\mathrm{H}$ bonds appear, respectively, at 1,500$1,660 \mathrm{~cm}^{-1}$ and $3,030 \mathrm{~cm}^{-1}$. The nitrogen in emeraldine base takes part in three bonds. The bond in $-\mathrm{N}-\mathrm{H}-$ amine manifests itself in peak lying between 3,300 and $3,500 \mathrm{~cm}^{-1}$ (stretch vibration-3,430 $\mathrm{cm}^{-1}$ ), peak ascribed to double $-\mathrm{C}=\mathrm{N}-$ appears at $1,150-1,170 \mathrm{~cm}^{-1}$ (vibration at $1,164 \mathrm{~cm}^{-1}$ ) and peak attributed to -C$\mathrm{N}-$ bond can be seen in the range $1,280-1,350 \mathrm{~cm}^{-1}$ (vibration at $1,308 \mathrm{~cm}^{-1}$ ).

\section{UV-vis spectroscopy}

In polyaniline UV-vis absorption spectrum it can be distinguished four characteristic bands at $305-330 \mathrm{~nm}, 420-450 \mathrm{~nm}, 620-650 \mathrm{~nm}$ and $760-800 \mathrm{~nm}$, related to following transitions $-\pi \rightarrow \pi^{*}$ in the benzenoid ring, polaron- $\pi^{*}, \pi \rightarrow \pi^{*}$ in the quinoid ring and $\pi$-polaron [25]. Relative intensities of these bands depend on the sample electrical conductivity. As a fingerprint of electrical conductivity is considered, part of the spectrum continuously rising towards NIR which is often

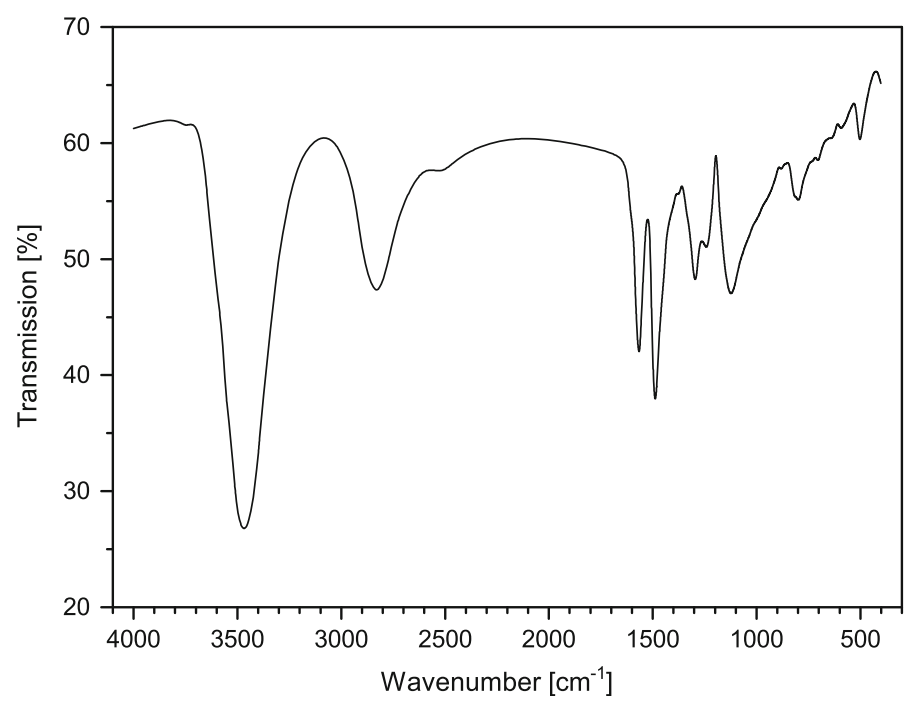

Fig. 2 FT-IR spectrum of the substance, obtained using UHP complex and identified as emeraldine base. Because of almost identical shape the other spectra are not shown 


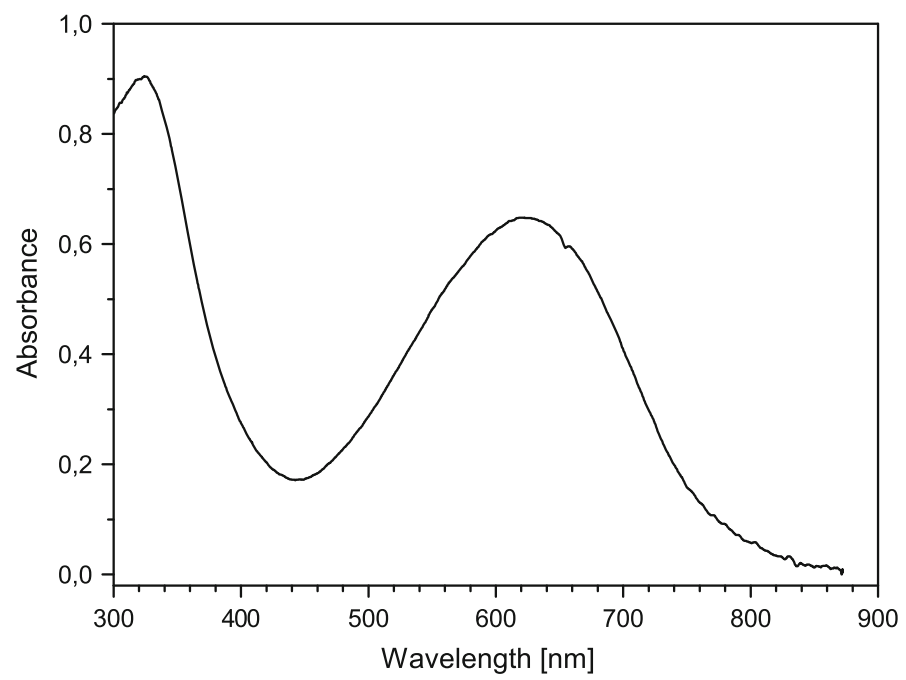

Fig. 3 UV-vis spectra of the product synthesised with the use of UHP oxidizer. The other were similar

referenced as free carrier tail. In the case of poor electrical conductivity transitions 620-650 nm and 760-800 nm should not be present.

$\mathrm{UV}$-vis absorption was measured in NMP ( $N$-methyl-pirrolidone) solution using a diode array spectrophotometer form Ocean Optics. NMP is a rare example of a non-protonating polyaniline solvent. All obtained spectra were very similar to the example shown in Fig. 3. There can be observed broad peaks characteristic of $\pi \rightarrow \pi^{*}$ transitions without any traces of transitions involving polarons. This observation confirmed that the studied products were product were emeraldine base form of polyaniline.

Thermogravimetric analysis

Thermal stability was studied through TG analysis, performed with a TA Instruments DTA-TGA 2960 SDT. A representative profile is shown in Fig. 4. The mass loss of the sample started at $20{ }^{\circ} \mathrm{C}$ and abruptly finished at $100{ }^{\circ} \mathrm{C}$. This effect frequently observed in different polymers, is interpreted as evaporation of absorbed moisture and/or residual solvent. However, the further behaviour was different than typically reported. The polymer degradation began just above $220^{\circ} \mathrm{C}$ (the most often cited temperature is closer to $300{ }^{\circ} \mathrm{C}$ ). The degradation was rather slow and the observed mass loss was less important than usually found in the bibliography. It did not exceed $23 \%$ at $600{ }^{\circ} \mathrm{C}$. This analysis confirmed above average heat resistance of the synthesised polyaniline.

Electrical conductivity

The electrical conductivity of pellets from $\mathrm{HCl}$ protonated polyaniline was measured by standard 4-points technique under argon atmosphere. Contact 


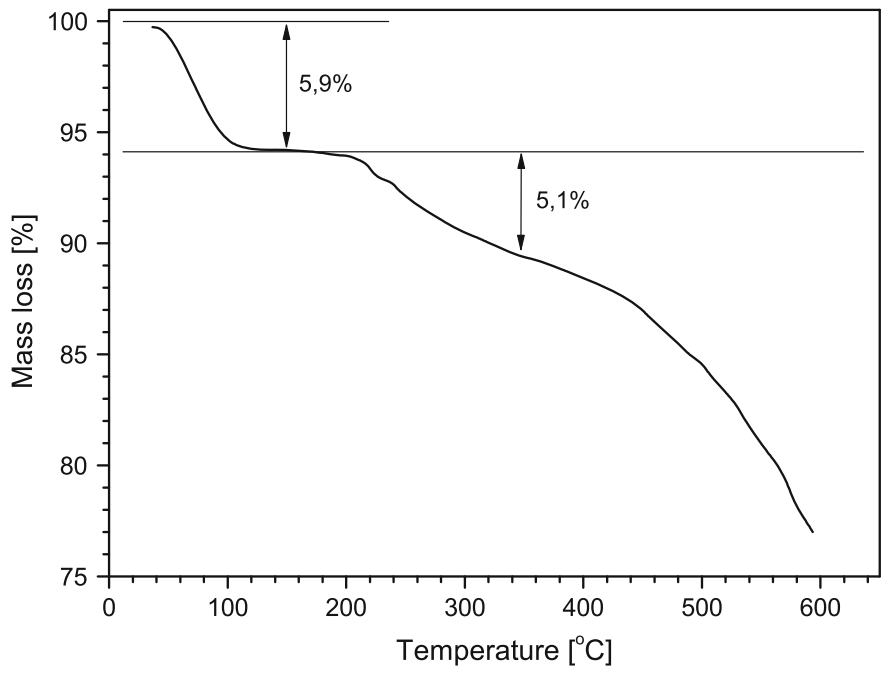

Fig. 4 TG curve of emeraldine base synthesised using UHP complex

electrodes were equidistant and arranged linearly (probing head from Jandel Ltd.). A Keithley $2400 \mathrm{I} / \mathrm{V}$ source supplied constant current through the outer contacts and voltage drop was measured between the inner ones using a Keithley 2000 DMM. Correcting factors imposed by the sample geometry, were adopted from the literature [26]. The electrical conductivity did not feature temporal variations. It was perfectly ohmic up to $5 \mathrm{~mA}$ - the maximum supplied current. Corresponding electrical conductivity values are collected in Table 2 and are in line of data typically reported for such systems [27]. Measurements of non-doped samples were performed in 2-point geometry. Leads were stuck with non-aggressive conducting glue and clamped in a Keithley 8002A high resistance text fixture coupled with a Keithley 487 picoammeter/voltage source. In all cases the sensitivity of the experimental setup (less then $10^{-12} \mathrm{~S} / \mathrm{cm}$ ) was insufficient to record coherent data.

\section{X-ray spectra}

The first exhaustive and systematic work [28] published at the beginning of 1990 systematizing and explaining crystalline structures of polyaniline, still remains main reference point for structural studies of different form of this polymer. In [28] two substantially different systems were proposed. They consisted of EB-I and EB-II

Table 2 Electrical conductivity found for $\mathrm{HCl}$-doped polyanilines

\begin{tabular}{lc}
\hline Sample & Value $(\mathrm{S} / \mathrm{cm})$ \\
\hline EB1-HCl & $2.8 \pm 0.5 \times 10^{-2}$ \\
EB2-HCl & $6.5 \pm 0.3 \times 10^{0}$ \\
EB4-HCl & $5.5 \pm 0.8 \times 10^{1}$ \\
\hline
\end{tabular}



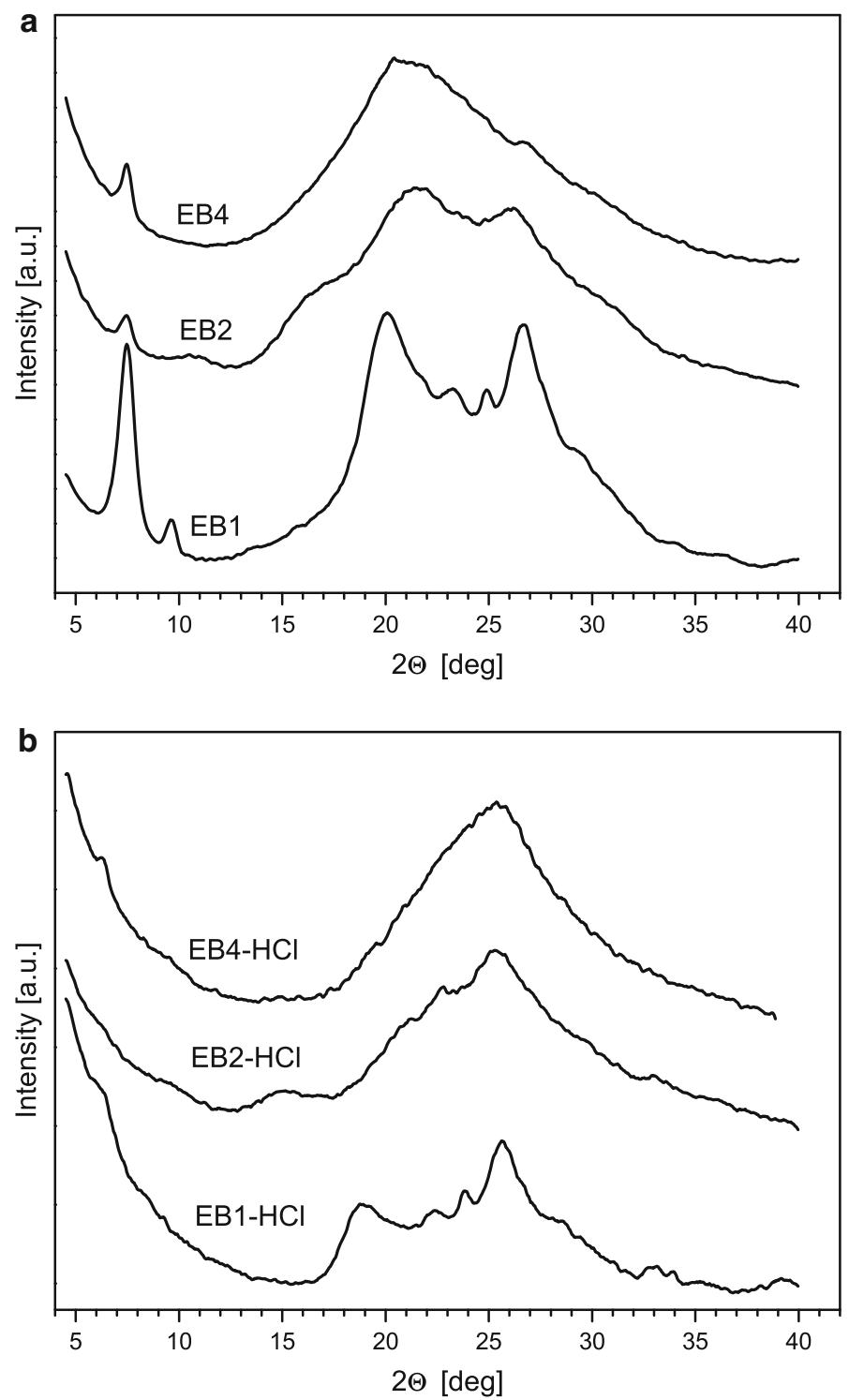

Fig. 5 Undoped (insulating) samples (a), doped (conductive) samples (b)

structures (for emeraldine base form) and related ES-I and ES-II (emeraldine). An EB can be converted in respective ES through protonation. Deprotonation does vice versa. ES-I structure is naturally adopted by the product directly resulting from chemical polymerization. The EB-I constitutes an amorphous structure what expresses in diffraction pattern consisting of only one very large maximum centred around $2 \theta \approx 19^{\circ}$ (related to the $\mathrm{CuK}_{\alpha}$ line). The EB-II form is observed in samples 
processed from some organic solvents like THF, NMP, DMSO. Beside the very distinct peak at $2 \theta \approx 19^{\circ}$ EB-II diffraction pattern exhibits also two less intense peaks at $2 \theta \approx 24^{\circ}$ and $2 \theta \approx 31^{\circ}$ what is explain as a proof of partial crystallinity. Shape of diffraction patterns of ES-I and ES-II is considerably different. In order to interpret patterns not fitting in these systems, it has been developed modifications taking into account a range of factors like water content, doping agent nature, preparation conditions or presence of plastifier [29]. Certain authors claimed also partial crystallinity in the case of EB-I [30], however, represented by a different diffraction pattern than characteristic of EB-II.

Wide angle X-ray diffraction measurements were carried out in parallel beam reflection and classical Bragg-Brentano geometry using $\mathrm{CuK}_{\alpha}$ line, using a PanAnalytical X'PertPRO diffractometer equipped with parallel beam parabolic Göbel mirror improving measured scattering intensities. In Fig. 5a, b are shown diffraction spectra measured for basic and protonated forms of the studied polyanilines. At the first glance one can notice a strong influence of the oxidizing agent type used in polymerization on diffraction patterns. In Fig. 5a one can easily distinguish two broad peaks at $2 \theta \approx 21^{\circ}$ and $2 \theta \approx 27^{\circ}$. In addition in the diffraction pattern of EB2 is present a hump at $2 \theta \approx 16^{\circ}$, which may arise from a superimposed less intensive peak. It may be concluded that the base form of the synthesised polyanilines was partially crystalline, resembling the structure of EB-II [31]. The lowest degree of crystallinity was found for EB4 and the highest for EB1. In Fig. 5b representing diffraction patterns of polyanilines conductive forms one can see that a well defined crystalline structure was retained only by $\mathrm{EB} 1-\mathrm{HCl}$, but ratios between characteristic peaks changed. It means that the protonation with $\mathrm{HCl}$ generally decreased crystallinity degree. It is a somewhat striking observation, because usually was observed a reverse effect [31, 32].

\section{Conclusions}

A modified method of aniline polymerization in the presence of solid state oxidizers (hydrogen peroxide complexes UHP, MHP, SCHP) has been developed. It is a practical, cost effective technology.

The polymerization yields were similar (or higher) than observed in classical polymerization using aqueous solution of hydrogen peroxide. The highest reaction output, approaching 60-65\%, was obtained when urea-hydrogen peroxide was employed as the oxidizing agent and aqueous $\mathrm{FeCl}_{2}$ solution as a catalyst. Other catalysts $\left(\mathrm{CoCl}_{2}, \mathrm{Ni}\left(\mathrm{NO}_{3}\right)_{2}\right.$ and $\left.\mathrm{CuCl}_{2}\right)$ gave maximum yields of 40,20 and $10 \%$, respectively (details will be published elsewhere). It is necessary to stress that $65 \%$ yield was reached just after $6 \mathrm{~h}$ of reaction. Despite the fact that the reaction was not optimized, this yield was close to reported by researchers from DuPont [33]. Physical experiments evidenced that the synthesized product was of qualities comparable to other polyanilines described in available bibliography.

It can be concluded that urea-hydrogen peroxide (UHP) may be successfully applied as a convenient oxidant in the polymerization of aniline, although this complex have been known so far as a component of pharmacological, cosmetics or 
household chemistry products with regard to its antiseptic, bleaching as well as disinfecting properties.

Acknowledgements Jacek Niziol and Maciek Sniechowski acknowledge active support from their home institution indicated in the affiliations.

Open Access This article is distributed under the terms of the Creative Commons Attribution Noncommercial License which permits any noncommercial use, distribution, and reproduction in any medium, provided the original author(s) and source are credited.

\section{References}

1. Skotheim TA, Reynolds J (eds) (2006) Conjugated polymers: theory, synthesis, properties, and characterization. Handbook of conducting polymers. CRC Press, Boca Raton

2. Macdiarmid AG, Chiang JC, Halpern M, Huang WS, Mu SL, Somasiri LD, Wu W, Yaniger SI (1985) Polyaniline: interconversion of metallic and insulating forms. Mol Cryst Liquid Cryst 121:173-180

3. Lee K, Cho S, Park SH, Heeger AJ, Lee CW, Lee SH (2006) Metallic transport in polyaniline. Nature 441:65-68

4. Hakansson E, Amiet A, Kaynak A (2006) Electromagnetic shielding properties of polypyrrole/ polyester composites in the 1-18GHz frequency range. Synth Met 156:917-925

5. Maziarz EP, Lorenz SA, White TP, Wood TD (2000) Polyaniline: a conductive polymer coating for durable nanospray emitters. J Am Soc Mass Spectrom 11:659-663

6. Chen Y, Wang XH, Li J, Lu JL, Wang FS (2007) Polyaniline for corrosion prevention of mild steel coupled with copper. Electrochim Acta 52:5392-5399

7. Baker CO, Shedd B, Innis PC, Whitten PG, Spinks GM, Wallace GG, Kaner RB (2007) Monolithic actuators from flash-welded polyaniline nanofibers. Adv Mater 20:155-158

8. Weder C, Greiner A (2001) In: Kroschwitz JI (ed) Encyclopedia of polymer science and technology. vol 3. Wiley-Interscience, New York, p 87

9. Horowitz G (1998) Organic field-effect transistors. Adv Mater 10:365-377

10. Brabec CJ, Sariciftci NS, Hummelen JC (2001) Plastic solar cells. Adv Funct Mater 11:15-26

11. Yan XB, Han ZJ, Yang Y, Tay BK (2007) $\mathrm{NO}_{2}$ gas sensing with polyaniline nanofibers synthesized by a facile aqueous/organic interfacial polymerization. Sens Actuators B 123:107-113

12. Łukasiewicz M, Pielichowski J (2004) A new heterogeneous catalyst for the oxidation of organic compounds by hydrogen peroxide. Pol J Chem Technol 6:31-33

13. MacDiarmid AG, Chiang JC, Richter AF, Somasiri NLD, Epstein JA (1987) In: Alcacer L (ed) Conducting polymers. Reidel, Dortrecht, pp 105-120

14. Genies EM, Łapkowski M (1988) Polyaniline films: electrochemical redox mechanisms. Synth Met 24:61-68

15. Kumar D, Sharma RS (1998) Advances in conductive polymers. Eur Polym J 34:1053-1060

16. Gosh P, Siddhanta SK, Haque SR, Chakrabarti A (2001) Stable polyaniline dispersions prepared in nonaqueous medium: synthesis and characterization. Synth Met 123:83-89

17. Genies EM, Boyle A, Łapkowski M, Tsintavis C (1990) Polyaniline: a historical survey. Synth Met 36:139-182

18. Pekmez N, Pekmez K, Arca M, Yildiz A (1993) The effect of monomer and acid concentrations on electrochemical polyaniline formation in acetonitrile. J Electroanal Chem 353:237-246

19. Cruz GJ, Morales J, Castillo-Ortega MM, Olayo R (1997) Synthesis of polyaniline films by plasma polymerization. Synth Met 88:213-218

20. MacDiarmid AG, Chiang JC (1986) 'Polyaniline': protonic acid doping of the emeraldine form to the metallic regime. Synth Met 13:193-205

21. Pron A, Genoud F, Menardo C, Nechtschein M (1998) The effect of the oxidation conditions on the chemical polymerization of polyaniline. Synth Met 24:193-201

22. Foke Y, Schlenoff JB (1995) Polymerization of aniline using mixed oxidizers. Polymer 36:639-643

23. Adams PN, Abell L, Middleton A, Monkman AP (1997) Low temperature synthesis of high molecular weight polyaniline using dichromate oxidant. Synth Met 84:61-62 
24. Wielicka J, Ptasiewicz-Malinowska A, Jędrych T, Minda M, Wiejak B, Pajer T, Ratajczak W, Michalska M, Capała W (2003) Disinfectants containing active oxygen: method for the preparation of urea hydroperoxide and melamine hydroperoxide. Pol J Chem Technol 5(3):19-21

25. Huang WS, MacDiarmid AG (1993) Optical properties of polyaniline. Polymer 34:1833-1845

26. Schroder DK (2006) Semiconductor material and device characterization. 3rd edn. Wiley-IEEE Press, New York

27. Wallace GG, Spinks GM, Kane-Maguire LAP, Teasdale PR (2009) Conductive electroactive polymers. CRC Press, Boca Raton

28. Pouget JP, Jozefowicz ME, Epstein AJ, Tang X, MacDiarmid AG (1991) X-ray structure of polyaniline. Macromolecules 24:779-789

29. Chaudhari HK, Kelkar DS (1996) X-ray diffraction study of doped polyaniline. J App Polym Sci 62:15-18

30. Winokur MJ, Mattes BR (1998) Structural studies of halogen acid doped polyaniline and the role of water hydration. Macromolecules 31:8183-8191

31. Luzny W, Sniechowski M, Laska J (2002) Structural properties of emeraldine base and the role of water contents: X-ray diffraction and computer modelling study. Synth Met 126:27-35

32. Sinha S, Bhadra S, Khastgir D (2009) Effect of dopant type on the properties of polyaniline. J Appl Polym Sci 112:3135-3140

33. de Oliveira ZT, dos Santos MC (2000) Semi-empirical study of chain conformation and absorption spectra of polyanilines: size, solvent and disorder effects. Chem Phys 260:95-103 